\title{
AVALIAÇÃO DE DIFERENTES AMIDOS COMO SUBSTRATO PARA O CULTIVO HETEROTRÓFICO DE MICROALGA
}

\author{
K. R. V. QUINHONES ${ }^{1}$, A. M. SANTOS ${ }^{1}$, E. C. FRANCISCO ${ }^{2}$, M.I. QUEIROZ ${ }^{3}$, L. Q. \\ ZEPKA $^{1}$ e E. JACOB-LOPES ${ }^{1}$ \\ ${ }^{1}$ Universidade Federal de Santa Maria, Departamento de Ciência e Tecnologia em \\ Alimentos \\ ${ }^{2}$ Universidade de Passo Fundo, Departamento de Engenharia Ambiental \\ ${ }^{3}$ Universidade Federal do Rio Grande, Escola de Química em Alimentos
}

E-mail para contato: jacoblopes@pq.cnpq.br

\begin{abstract}
RESUMO - A escolha de insumos de baixo custo para a formulação de meios de cultura é de grande importância para a economia global de processos biotecnológicos, uma vez que representam um percentual significativo no custo final do produto. Neste sentido o objetivo do estudo foi realizar uma avaliação de diferentes tipos de amido (mandioca e milho) como substrato para o cultivo heterotrófico da microalga Aphanothece microscopica Nägeli. Os experimentos foram conduzidos em um biorreator de coluna de bolhas com relação altura/diâmetro (L/D) igual a 1,28 , com volume de trabalho de $2 \mathrm{~L}$. As condições experimentais utilizadas foram: razão carbono/nitrogênio de 68 , concentração inicial de $100 \mathrm{mg} / \mathrm{L}, \mathrm{pH}$ de 7,6 , temperatura de $30^{\circ} \mathrm{C}$, aeração constante de $1 \mathrm{VVM}$ (volume de ar por volume de meio por minuto) e ausência de luminosidade. Foram avaliadas a concentração celular e o consumo de carbono orgânico a cada 24 horas durante as fases de crescimento do microrganismo. Os resultados obtidos indicaram que a máxima concentração celular foi de $8830 \mathrm{mg} / \mathrm{L}$.h para o amido de mandioca e de 5630 mg/L.h para o amido de milho, com taxas de consumo de substrato de 44,13 $\mathrm{mg} / \mathrm{L} . \mathrm{h}$ e $24,7 \mathrm{mg} / \mathrm{L} . \mathrm{h}$, respectivamente.
\end{abstract}

\section{INTRODUÇÃO}

Microalgas são organismos fotossintetizantes que utilizam o $\mathrm{CO}_{2}$ do ar e luz solar para o seu crescimento. Uma das possibilidades para melhorar as taxas de crescimento desses microorganismos é a modificação do regime de cultivo, através da adição de um componente carbônico orgânico ao meio.

O desenvolvimento de células de microalgas em zonas afóticas, associado à manutenção destas estruturas celulares nos períodos de escuro, durante o fotoperíodo diário, indica a possibilidade de utilizar tecnologicamente rotas metabólicas heterotróficas para o cultivo microalgal (PEREZ-GARCIA et al., 2011). Desta forma, a heterotrofia pode ser definida como a utilização exclusivamente de compostos orgânicos exógenos como fonte de carbono e 
de energia, permitindo o cultivo de células microalgais (CHOJNACKA \& MARQUEZROCHA, 2004).

As fontes de carbono mais utilizadas para cultivo heterotrófico de microalgas e cianobactérias são acetato e glicose (SHI et al., 1999), e uma substituição destas fontes de carbono por outros substratos orgânicos de baixo custo, como os amidos seria uma alternativa para atenuar os custos do processo (Li et al., 2007). Os amidos são polissacarídeos naturais constituídos basicamente por polímeros de $\alpha$-D-glicose: amilose e amilopectina. Quando hidrolisadas, as frações do amido clivam-se lentamente, originando dextrina, maltose e finalmente glicose (BULÉON et al., 1998).

As informações acerca das condições de uso destes substratos orgânicos para o cultivo microalgal são atualmente limitadas (BONINI; BASTOS, 2012; PEREZ-GARCIA et al., 2011), e sendo assim, o objetivo deste trabalho é avaliar diferentes tipos de amido (mandioca e milho) como substrato para o cultivo heterotrófico da microalga Aphanothece microscopica Nägeli.

\section{MATERIAL E MÉTODOS}

\subsection{Microrganismo e Meio de Cultura}

A microalga utilizada foi a Aphanothece microscopica Nägeli, as culturas estoques foram propagadas e mantidas em meio sintético padrão BGN (Rippka et al., 1979) com a seguinte composição: $\mathrm{K}_{2} \mathrm{HPO}_{4}\left(3 \mathrm{~g} .100 \mathrm{~mL}^{-1}\right), \mathrm{MgSO}_{4} \cdot 7 \mathrm{H}_{2} \mathrm{O}\left(7,5 \mathrm{~g} \cdot 100 \mathrm{~mL}^{-1}\right), \mathrm{CaCl}_{2} \cdot 2 \mathrm{H}_{2} \mathrm{O}$ (3,6g. $\left.100 \mathrm{~mL}^{-1}\right)$, Citrato de amônio e ferro III $\left(0,6 \mathrm{~g} \cdot 100 \mathrm{~mL}^{-1}\right), \mathrm{Na}_{2} \operatorname{EDTA}\left(0,1 \mathrm{~g} \cdot 100 \mathrm{~mL}^{-1}\right)$, $\mathrm{NaCl}\left(7,2 \mathrm{~g} .100 \mathrm{~mL}^{-1}\right), \mathrm{NaNO}_{3}\left(150 \mathrm{~g} \cdot \mathrm{L}^{-1}\right)$, Ácido cítrico $\left(0,06 \mathrm{~g} .100 \mathrm{~mL}^{-1}\right), \mathrm{Na}_{2} \mathrm{CO}_{3}(0,2 \mathrm{~g}$. $\left.100 \mathrm{~mL}^{-1}\right), \quad \mathrm{H}_{3} \mathrm{BO}_{3} \quad\left(2,86 \mathrm{~g} . \mathrm{L}^{-1}\right), \quad \mathrm{MnCl}_{2} \cdot 4 \mathrm{H}_{2} \mathrm{O} \quad\left(1,816 \mathrm{~g} \cdot \mathrm{L}^{-1}\right), \quad \mathrm{ZnSO}_{4} \cdot 7 \mathrm{H}_{2} \mathrm{O} \quad\left(0.222 \mathrm{~g} . \mathrm{L}^{-1}\right)$, $\mathrm{Na}_{2} \mathrm{MoO}_{4} \cdot 2 \mathrm{H}_{2} \mathrm{O}\left(0,390 \mathrm{~g} \cdot \mathrm{L}^{-1}\right), \mathrm{CuSO}_{4} \cdot 5 \mathrm{H}_{2} \mathrm{O}\left(0,079 \mathrm{~g} \cdot \mathrm{L}^{-1}\right), \mathrm{CaCl}_{2} \cdot 6 \mathrm{H}_{2} \mathrm{O}\left(0,040 \mathrm{~g} \cdot \mathrm{L}^{-1}\right)$.

\subsection{Biorreator e condições de cultivo}

Os experimentos foram conduzidos em um biorreator de coluna de bolhas com relação altura/diâmetro (L/D) igual a 1,28, com volume de trabalho de $2 \mathrm{~L}$. O meio de cultivo consistiu em meio sintético BGN suplementado com amido de milho e/ou amido de mandioca, visando obter uma razão $\mathrm{C} / \mathrm{N}$ de 68 através de ajustes estequiométricos e preparo de curvas padrão dos respectivos amidos. As condições experimentais foram $100 \mathrm{mg} / \mathrm{L}$ de 
inóculo da cianobactéria Aphanothece microscopica Nägeli, $\mathrm{pH}$ de 7,6, temperatura de $30^{\circ} \mathrm{C}$, aeração contínua de 1VVM (volume de ar por volume de meio por minuto) e ausência de luminosidade. Os ensaios foram conduzidos em meio de cultivo BGN contendo 20g/L de amido de milho e posteriormente o ensaio foi repetido nas mesmas condições, utilizando-se 20g/L de amido de mandioca.

\subsection{Amostragem e métodos analíticos}

As amostras foram coletadas em intervalos de $24 \mathrm{~h}$ e caracterizadas quanto ao $\mathrm{pH}$, demanda química de oxigênio (DQO) e concentração celular. $\mathrm{O}$ pH foi determinado por potenciometria, a demanda química de oxigênio foi determinada conforme a metodologia descrita no Standard Methods for the Examination of Water and Wastewater (APHA, 2005). A concentração celular foi determinada gravimetricamente por meio da filtração de um volume conhecido do meio de cultivo em filtro de $0,45 \mu \mathrm{m}$ de diâmetro. Os testes foram realizados em duplicata e os dados cinéticos referem-se à média de duas repetições.

\section{RESULTADOS E DISCUSSÃO}

Os parâmetros cinéticos utilizando o amido de mandioca e milho como fonte de carbono exógena para a cultura heterotrófica da microalga Aphanothece microscopica Nägeli são apresentados na Tabela 1.

Tabela 1. Parâmetros cinéticos do processo

\begin{tabular}{ccc}
\hline Parâmetros cinéticos & Amido de Mandioca & Amido de Milho \\
\hline rC (mg/L.h) & 44,13 & 24,7 \\
X $(\%)$ & 88,74 & 49,51 \\
$\mu_{\text {máx }}\left(\mathrm{h}^{-1}\right)$ & 0,012 & 0,011 \\
$\operatorname{tg}(\mathrm{h})$ & 57,7 & 63,0 \\
$\mathrm{X}_{\text {máx. }}\left(\mathrm{mg} \mathrm{L}^{-1}\right)$ & 8830 & 5630 \\
\hline
\end{tabular}

rC (DQO): taxa de remoção de DQO, X:conversão de amido; $\mu$ max: velocidade específica de crescimento máxima; tg: tempo de geração e $X_{\text {máx. }}$ concentração celular máxima, respectivamente.

A análise dos dados indica que o amido de mandioca foi o substrato de melhor desempenho para o cultivo heterotrófico da Aphanothece microscopica Nägeli, quando considerados os parâmetros cinéticos de crescimento celular e consumo de substrato. 
A variabilidade dos resultados entre os respectivos substratos são uma função dos teores de amilose e amilopectina presentes nos amidos, sendo que o teor de amilose e amilopectina para o amido de milho é de $24 \%$ e $76 \%$ e para o amido de mandioca são de $17 \%$ e $83 \%$, respectivamente (MARCON et al., 2007). A presença de maiores concentrações de amilopectina, nos amidos de mandioca favorece o desempenho microalgal, uma vez que as reservas endógenas destes micro-organismos são constituídas do chamado amido cianofíceo, que é composto por $\alpha$-1,4-glucana, com composição simular ao glicogênio e a amilopectina presente nos amidos de plantas superiores (Francisco et al., 2014). Neste sentido, as células de cianobactérias já estão previamente aclimatadas ao substrato, o que resulta em desempenhos superiores dos cultivos baseados em amidos com elevadas proporções de amilopectina.

\section{CONCLUSÃO}

Os resultados demonstraram que a Aphanothece microscopica Nägeli foi capaz de metabolizar com eficiência os amidos de mandioca e milho sem a necessidade prévia de hidrólise.

O amido de mandioca foi à fonte orgânica de carbono de maior potencial de exploração, em função do desempenho cinético obtido no consumo de substrato e crescimento celular.

\section{REFERÊNCIAS}

APHA, AWWA, WEF (American Public Health Association, American Waterworks Association. Water Environmental Federation). Standard Methods for the Examination of Water and Wastewater, 21st ed. Prot City Press, Baltimore, Maryland, p.1325, 2005.

BONINI, A. M., BASTOS, R. G., Produção de biomassa de Aphanothece microscopica e Chlorella vulgaris por cultivo heterotrófico a partir de Glicose. Ciências Biológicas e da Saúde, Londrina, v. 33, n. 2, p. 151-160, jul./dez. 2012

BULEÓN, A; COLONNA, P.; PLANCHOT, V.; BALL, S. Starch granules: structure and biosynsthesis. International Journal of Biological Macromolecules, v. 23, p. 82-112, 1998.

CHOJNACKA, K.; MARQUEZ-ROCHA, F. J. Kinetic and stoichiometric relationships of the energy and carbon metabolism in the culture of microalgae. Biotechnology, Dickson, v. 3, n. 1, p. 21-34, 2004. 
FRANCISCO, E. C.; FRANCO, T.T.; WAGNER, R.; JACOB-LOPES, E., Assessment of diffrent carbohydrates as exogenous carbon source in cultivation. Bioprocess Biosyst Eng, 2014.

LI, X.; XU, H.; WU, Q. Large-scale biodiesel production from microalga Chlorella protothecoides through heterotrophic cultivation in bioreactors. Biotechnol. Bioen., v. 98, p. 4, p.764-771, 2007.

MARCON , M. J. A.; AVANCINI, S. G. P.; AMANTE E. R., Propriedades químicas e tecnológicas do amido de mandioca e do polvilho azedo, Ed. UFSC, SC, 2007.

PEREZ-GARCIA, O.; ESCALANTE, F. M. E., LUZ-BASAN, E., BASAN, Y., Heterotrophic cultures of microalgae: Metabolism and potential products. Water Research, 2011.

RIPPKA R, DERULLES J, WATRERBURY JB, HERDMAN M, STAINER RY. Generic assignments, strain histories and properties of pure cultures of cyanobacteria. Journal of General Microbiology, n.111 p.1-61, 1979.

SHI, X.-M., LIU, H.-J., ZHANG, X.-W., CHEN, F., Production of biomass and lutein by Chlorella protothecoides at various glucose concentrations in heterotrophic cultures. Process Biochem. 34, 341e347. 1999. 